\title{
A Remote Cause of Vomiting: Case Report on Pan-Hypopituitarism
}

\author{
Shibil.Pk ${ }^{1 \star}$, Mahira Maideen ${ }^{1}$, Saju Xavier ${ }^{2}$, Azimudin ${ }^{2}$, Dilip. ${ }^{3}$, Hridya Mary Thomas ${ }^{1}$ and Elizabeth \\ Joseph $^{1}$
}

${ }^{1}$ Pharm D Interns, Department Of Pharmacy Practice, Al-Shifa College Of Pharmacy, Kizhattur, Perinthalmanna, Malappuram, Kerala, INDIA.

${ }^{2}$ Department Of Gastroenterology, Kims Al-Shifa Hospital, Perinthalmanna, Malappuram, Kerala, INDIA.

Hod,

${ }^{3}$ Department Of Pharmacy Practice, Al - Shifa College Of Pharmacy, Perinthalmanna, Kerala, INDIA.

\begin{abstract}
Pan-hypopituitarism is the inability of the pituitary gland to provide sufficient hormones due to an in sufficient supply of hypothalamic releasing hormones. A46 year old female patient was admitted to the department of gastroenterology with chief complaints history of vomiting since 4 months (5- 10 minfollowing feed), weakness and weight preserved. All Endo-crinological work up was not normal. MRI brain (PIT protocol)came with Empty sella with infundibulum central with flattened anterior pituitary. She had attained menopause at age of 30 years $3-4$ years following the birth of her $3^{\text {rd }}$ female child. She had diagnosed with Empty Sella Syndrome, Anterior Pituitary Hypoplasia, and Sheehan's Syndrome. Finallyshe was treated with prednisone $10 \mathrm{mg}(5 \mathrm{mg}$ at morning and $5 \mathrm{mg}$ at evening) and Levothyroxine $50 \mathrm{mcg}$ daily before breakfast. Further workup with DEXA bone scans and plan hormone replacement Serial measurement of hormone assay.
\end{abstract}

Key words: Vomiting, Pan-hypopituitarism, empty sella syndrome, sheehans syndrome,levothyroxine

\section{INTRODUCTION}

Hypopituitarism is a state of endocrinal malfunction - partial or complete - resulting from diseases of pituitary, hypothalamus, or even surrounding structures. ${ }^{1}$ Regal et al reported a prevalence of 45/ 100000 and an incidence of about $4 / 100000 /$ year in the normal population, with nearly $50 \%$ of patients having three to five pituitary hormone deficits. It is a complex medical condition associated with a higher mortality than that of the general population. ${ }^{6}$ Hypopituitarism may involve the loss of one, several or all of the pituitary hormones. Thus, a complete evaluation is needed to determine which hormone or hormones are deficient and need to be replaced. Hormone replacement is available for all of the pituitary hormones except for PRL and oxytocin. ${ }^{2}$

To determine a specific cause for the hypopituitarism, a head MRI (with intravenous administration of contrast dye) must be performed. A CAT scan does not provide the same degree of resolution. Causes of congenital (from birth) hypopituitarism that can be detected by MRI include a transected DOI: 10.5530/ijopp.9.3.15 or interrupted hypothalamic-pituitary stalk and various "midline defect syndromes" (groupings of medical problems involving structures in the middle of the brain, such as septo-optic dysplasia, in which there may be absence of the midline brain structure known as the septum pellucidum and underdevelopment of the optic nerves associated with variable degrees of reduced vision). Causes of acquired hypopituitarism that can be detected by MRI include tumors in the hypothalamic-pituitary region, the most common one of which in childhood is a craniopharyngioma. If there are no associated radiological abnormalities, the hypopituitarism is said to have an idiopathic basis. ${ }^{3}$
Address for correspondence: Shibil.Pk,

Pharm D Interns, Department Of Pharmacy Practice, Al-Shifa College Of Pharmacy, Kizhattur, Perinthalmanna, Malappuram, Kerala, INDIA.

Contact: 919605509477

E-mail id:shibilpharma@gmail. com 
To characterize the extent of the hypopituitarism, appropriate testing for all clinically relevant pituitary hormones needs to be undertaken. GH is the most commonly affected pituitary hormone in childhood hypopituitarism. Thus, the initial clue to the diagnosis of hypopituitarism is almost always short stature and slow growth, testing for which then confirms the diagnosis of GH deficiency and begins the process of investigation for other hormonal deficiencies. Deficiency of TSH causes central hypothyroidism (thyroid hormone deficiency). Unlike children whose hypothyroidism is due to thyroid gland damage, those with hypopituitarism typically have somewhat higher thyroid hormone levels and, thus, may have little or no symptoms, but sometimes present, like those patients with primary thyroid disease, with short stature and slow height velocity, relative weight excess, constipation, dry skin, and fatigue. A low total and/or free thyroxine ( $\mathrm{T}$ 4) level with a normal or low TSH level confirms the diagnosis of central hypothyroidism. Younger children with deficiencies of the gonadotropins (luteinizing hormone $=\mathrm{LH}$ and follicle-stimulating hormone $=$ FSH) show no abnormalities as, prior to puberty, these levels are normally very low. In contrast, older, adolescent-aged children with deficiencies of the gonadotropins present with failure to start or continue with puberty (breast development and menstrual periods in girls and enlargement of the penis and testicles in boys). During this age period, low levels of $\mathrm{LH}$ and FSH, along with a pelvic ultrasound in females that shows prepubertal-sized ovaries and uterus, may be diagnostic.

Loss of ACTH causes adrenal insufficiency (cortisol deficiency). This is the most likely hormone, if deficient, to place a child in a life-threatening situation. While there would likely be no symptoms under normal circumstances, except maybe mild fatigue, lack of ACTH and cortisol in the setting of infection, fever, surgery, etc., may cause vomiting, dehydration, shock, and even death. It is, therefore, imperative to have this hormonal system evaluated. Testing usually requires some sort of stimulation, such as with insulin, metyrapone, or low-dose ACTH. ADH (also known as vasopressin) from the posterior or rear portion of the pituitary gland, if deficient, causes central or neurogenic diabetes insipidus (DI). Infants and toddlers manifest diabetes insipidus with excessively wet diapers. If unrecognized and, hence, untreated, in this age group, dehydration with elevated salt (sodium) concentrations in the blood ensues, as young children cannot report and easily satisfy heightened thirst. Older children with DI typically present with excessive day- and night-time urination, new onset of bed-wetting, and increased thirst. DI most often occurs unintentionally as a result of surgical treatment of a hypothalamic pituitary tumor. In some cases, DI is temporary due to surgical swelling, but it will be permanent if surgical sacrifice close to the hypothalamus was required for complete cure of a brain tumor in the vicinity.

CASE REPORT: A 46 year old female patient was admitted to the department of gastroenterology with chief complaints history of vomiting since 4 months (5- 10 minutes following feed), weakness and weight preserved. On physical examination she was found to be a thin built poorly nourished adult female with Weight $38 \mathrm{~kg}$, BP $120 / 80 \mathrm{mmHg}$ Pallor +, icterus -, lymph node-, cardiac and respiration examination was normal. Soft BS+ no mass/free fluid-. Her previous diagnostic report of imaging USG abdomen was normal. Oesophagus, gastro-duodenalscopy was normal up to duodenal $2^{\text {nd }}$ part. She had hypoglycemia on multiple occasions. Therefore it was suspected as a benign gastric outlet obstruction.Furtherworkup was to assess the upper GI tract for any obstructive lesions by endoscopy and to view the possible organ affected to find the extent of disease.

From examining the various reports the physician could not arrive at a possible diagnosis. She was prescribed Intravenous fluids (Normal Saline, Ringer Lactate and Dextrose Normal Saline) at the rate of $150 \mathrm{ml} / \mathrm{hr}$ on the first day. Injection Ondanesetron $8 \mathrm{mg}$ TID, Pantoprazole $40 \mathrm{mg} \mathrm{BD}$ and Potassium Chloride $2 \mathrm{amp}$ in $500 \mathrm{ml} \mathrm{NS}$. On the first day her ESR was elevated to $45 \mathrm{~mm} / \mathrm{hr}$, Serum sodium decreased to $101 \mathrm{meq} / \mathrm{L}$ and Serum potassium decreased to $2.6 \mathrm{meq} / \mathrm{L}$.

On the second day Injection Ondanesetron8mg TID, Pantoprazole $40 \mathrm{mg} \mathrm{BD}$ and Potassium Chloride $\mathrm{Kcl}$ 2 amp in $500 \mathrm{ml}$ NS was continued and 3\% Saline $100 \mathrm{ml}$ over $4 \mathrm{hr}$ was given to replenish the sodium. The lab parameters like Serum cortisol was $60.03 \mathrm{ng} / \mathrm{ml}$, Serum LH $0.94 \mathrm{mIU} / \mathrm{ml}$, Serum FSH $6.41 \mathrm{mIU} / \mathrm{ml}$, Serum prolactin $19.17 \mathrm{ng} / \mathrm{ml}$, T3 $1.67 \mathrm{Pg} / \mathrm{ml}$, T4 0.46 $\mathrm{Pg} / \mathrm{ml}$ were all decreased. Serum sodium $112 \mathrm{meq}$, Serum potassium 3.7 meq was slowly improving. She had attained menopause at age of 30 years 3-4 years following the birth of her 3rd female child. On the third day InjectionOndanesetron8mg TID, Injection Pantoprazole $40 \mathrm{mg}$ BD,Syrup Potassium Chloride 15ml TID and Injection Metoclopramide 1 amp soswas given. On the fourth day Ondanesetron 8mg TID, Injection Pantoprazole $40 \mathrm{mg}$ BD, Syrup Potassium Chloride $15 \mathrm{ml}$ TIDwas continued along withTablet Prednisolone $10 \mathrm{mg} 5 \mathrm{mg}$ at morning and $5 \mathrm{mg}$ at night and Tablet Levothyroxine $50 \mathrm{mcg}$ OD before breakfast was given. The MRI ofBrain(PIT protocol) showed Empty sella with infundibulum central with flattened anterior 
pituitary. Posterior pituitary was normal. The drugs were continued on the fifth day. The patient was diagnosed with Empty Sella Syndrome or Anti Pituitary Hypoplasia or Sheehan's Syndrome. The final diagnosis was Pan-Hypopituitarism. The patient was discharged with Tablet Levothyroxine $50 \mathrm{mcg}$ morning on empty stomach for 15 days, Tablet Prednisolone $10 \mathrm{mg}$ 1/2-0-1/2 mg for 15 days, Tablet Domperidone10 mg SOS and Tablet Pantoprazole $40 \mathrm{mg}$ before breakfast for 15 days.

\section{MRI BRAIN(PIT protocol)}

- Empty sella with infundibulum central with flattened anterior pituitary.

- Posterior pituitary normal
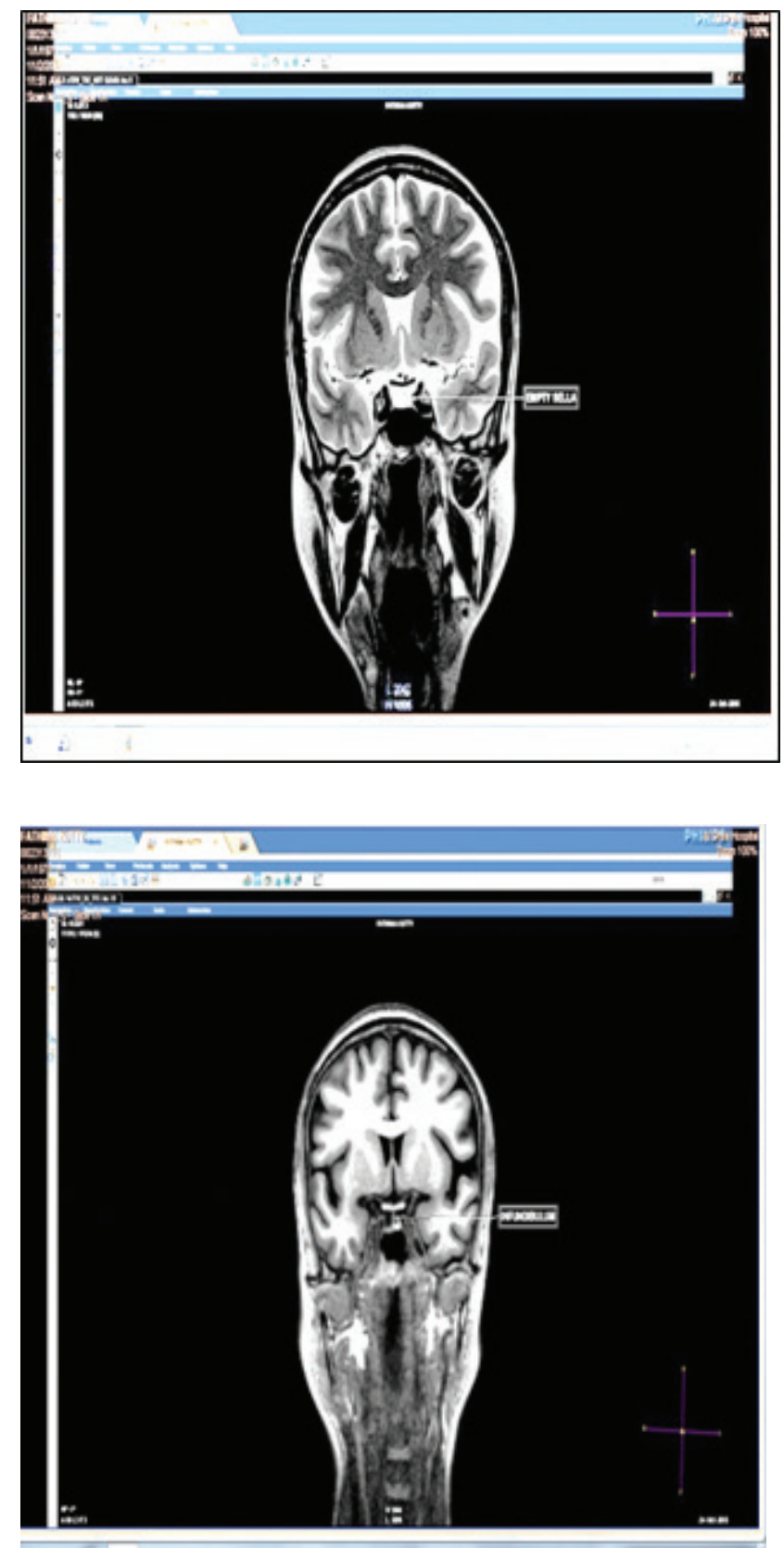


\section{DISCUSSION}

There are numerous causes of hypopituitarism. The most common cause of hypopituitarism is a pituitary tumor (also known as a pituitary adenoma). Pituitary adenomas are almost invariably benign (not cancerous). However, the pituitary adenoma itself may put pressure on the remaining normal part of the pituitary gland and limit or even destroy its ability to produce hormones appropriately.may involve the loss of one, several or all of the pituitary hormones. Thus, a complete evaluation is needed to determine which hormone or hormones are deficient and need to be replaced. Hormone replacement is available for all of the pituitary hormones except for PRL and oxytocin. Sometimes pituitary adenomas produce too much of one hormone (e.g., GH or PRL), 
which is called hyper pituitarism, while simultaneously causing underproduction of other hormones produced in the adjacent normal pituitary gland. In this case, reduced levels of some hormones (e.g., hypopituitarism due to thyroid, adrenal, and sex hormone dysfunction) can be accompanied by overproduction of other hormones. Hypopituitarism can also result from pituitary surgery, which might damage part of the normal pituitary. It can result from radiation treatment that, over time, also might damage the normal pituitary, even if the pituitary gland was working normally when the patient was first diagnosed with the pituitary adenoma. Therefore, a full pituitary hormone assessment is required both before and after surgery or radiation treatment. Other tumors that grow near the pituitary gland (e.g., craniopharyngioma, Rathke's cleft cyst) can cause hypopituitarism. In addition, tumors that metastasize from cancers elsewhere in the body can spread to the pituitary gland and can lead to hypopituitarism.Corticotrophin (ACTH) deficit presents as fatigue, weakness, abdominal pain, and altered mental activity. Physical examination reveals hypotension, loss of axillary and pubic hair and absence of any pigmentation as typically seen in Addison's disease. Although normocytic, normochromic anaemia with eosinophilia, hyponatraemia are observed as in primary adrenal failure, but hyperkalaemia is typically absent in Sheehan's syndrome. Secondary hypothyroidism manifests as weight gain, constipation, and cold intolerance. Physical examination reveals bradycardia, periorbital puffiness and delayed tendon reflexes.

Gonadotrophins (FSH and LH) deficit in women present with altered menstrual functions with regular anovulatory cycles or amenorrhoea with varying degrees of hot flushes, vaginal dryness, and dyspareunia. Pubic and axillary hair may be present unless associated with adrenal failure.

Growth hormone (GH) deficiency in adults leads to reduced vigour, decreased exercise tolerance, and worsening of quality of life with increased percentage of body fat.

Hyperprolactinaemia, which is commonly observed in prolactin secreting tumour or any process that interferes in transport of dopamine from hypothalamus to pituitary, is typically absent in Sheehan's syndrome.

Vasopressin deficiency of posterior pituitary leads to diabetes insipidus presenting as polyuria and polydipsia with nocturia and cold water preference. Oxytocin deficiency causes decreased milk ejection during lactation.

Endocrinal and imaging studies have special role in investigating hypopituitarism. Basal hormone level is all that is needed to confirm insufficiency, but dynamic tests are required if serum hormones levels are equivocal or to diagnose partial deficiency. As regards imaging, contrast MRI is superior to CT as optic chiasma, pituitary stalk, and cavernous sinuses - all of which may be affected by hypothalamic or pituitary mass - are better evaluated with it. High resolution CT scan with contrast in coronal sections with thin slice $(1.5 \mathrm{~mm})$ is an adequate alternative. Skull and sellar radiographs have little role as tumours may extend superiorly or laterally without enlarging the sella.

Management of these patients certainly includes proper hormonal replacement. Cortisol and thyroxine are required life-long as their deficiency may lead to high incidence of mortality. Gonadotrophins deficiency causing infertility and sexual dysfunction may not be a problem in particular patients. Replacement is required to reduce the incidence of decreased bone density and increased risk of osteoporosis in deficient patients. Oestrogen deficiency causes increased coronary artery disease, thus replacement being necessary to reduce the incidence of CAD. Prolactin is not known to cause any long-term problem except deficient lactation. Adrenal insufficiency should be treated at suspicion and definitive diagnosis made post-therapy. Cortisol replacement should precede thyroxine to avoid Addisonian crisis. ${ }^{1}$

\section{ACKNOWLEDGEMENT}

We take this great opportunity to thank KIMS al shifa hospital and its institutions to providing necessary facilities and continuous support in all our activities.

\section{REFERENCES}

1. AtulBhasin RK Singal: case report onpanhypopitutarism.JIACM. 2007;8(3):256-9.

2. Goswami R, Kochupillai $\mathrm{N}$ et al. Pituitary Autoimmunity in patients with Sheehan's syndrome. The Journal of Clinical Endocrinology and Metabolism. (2002);87(9):4137-41. http://dx.doi.org/10.1210/jc.2001-020242; PMid:12213861.

3. Regal M, Paramo C, Sierra SM, et al. Prevalence and incidence of hypopituitarism in an adult Caucasian population in northwestern Spain. ClinEndocrinol (Oxf). 2001;55(6):735-40. http://dx.doi.org/10.1046/j.13652265.2001.01406.x.

4. Rosen T, Bengtsson B-A. Premature mortality due to cardiovascular disease in hypopituitarism. Lancet. 1990;336(8710):285-8. http://dx.doi.org/10.1016/01406736(90)91812-O.

5. Bates AS, Van't Hoff W, Jones PJ, et al. The effect of hypopituitarism on life expectancy. J ClinEndocrinolMetab. 1996;81(3):1169-72. http://dx.doi. org/10.1210/jcem.81.3.8772595; http://dx.doi.org/10.1210/jc.81.3.1169.

6. Bulow B, Hagmart L, Mikoczy Z, et al. Increased cerebrovascular mortality in patients with hypopituitarism. ClinEndocrinol (Oxf). 1997;46(1):75-81. http:// dx.doi.org/10.1046/j.1365-2265.1997.d01-1749.x .

7. Tomlinson JW, Holden N, Hills RK, et al. Association between premature mortality and hypopituitarism. Lancet. 6 Vance ML. Hypopituitarism.NEngl J Med. 2001;357(9254):425-31

8. Arafah BM. Reversible hypopituitarism in patients with large nonfunctioning pituitary adenomas. J ClinEndocrinolMetab. 1986;62(6):1173-9. http://dx.doi. org/10.1210/jcem-62-6-1173; PMid:3009521.

9. Arafah BM, Prunty D, Ybarra J, et al. The dominant role of increased intrasellarpressure in the pathogenesis of hypopituitarism, hyperprolactinemia, and headaches in patients with pituitary adenomas. J Clin Endocrinol Metab. 2000;85(5):1789-93. http://dx.doi.org/10.1210/jc.85.5.1789: http://dx.doi. org/10.1210/jcem.85.5.6611; PMid:10843153. 